\title{
Particularities of High Oxygen Content Biofuels Pyrolysis Process
}

\author{
G. Lazaroiu ${ }^{1}$, L. Mihaescu ${ }^{2}$, E. Pop ${ }^{2}$, R.M. Grigoriu ${ }^{1}$, D.A. Ciupageanu ${ }^{1}$, and I. Simion ${ }^{1}$ \\ ${ }^{1}$ Power Engineering Faculty \\ University Politehnica of Bucharest, Romania \\ Splaiul Independentei 313, 060042 Bucharest (Romania) \\ e-mail: glazaroiu@yahoo.com, manuela.grigoriu.1968@gmail.com, dana ciupageanu@yahoo.com, \\ julia.simion@gmail.com \\ ${ }^{2}$ Mechanics and Mechatronics Faculty \\ University Politehnica of Bucharest, Romania \\ Splaiul Independentei 313, 060042 Bucharest (Romania) \\ e-mail: 1mihaescu48@gmail.com, elena.popo@upb.ro
}

\begin{abstract}
Generating capacities supplied by solid biomass (renewable waste) gather at the moment less than $4.5 \%$ of the total renewable power installed worldwide. Given the two folded implications of such technology development and spreading (i.e. energy production and waste management), researches regarding efficient conversion processes and improved power facilities are of great interest currently. In this context, the paper addresses the particularities of high oxygen content biofuels pyrolysis, proposing innovative solutions to overcome the issues found in experimental investigations. Based on thorough experimental research conducted on agricultural wooden biomass and poultry manure, a number of problems arise. Among them, it is highlighted the heating in the absence of oxidants, an undesirable internal process caused by the high oxygen content, which contravenes the general principles regarding pyrolysis. Furthermore, the high oxygen content is associated with great moisture percentages.

The present paper reveals the challenges determined by some negative aspects emerging during the pyrolysis of high oxygen content biofuels. Several solutions are proposed to improve the efficiency of the conversion process through adequate control. For instance, it is pointed out that the temperature level at which the pyrolysis process develops plays a crucial role in the general energy balance. On this matter, investigating poultry manure pyrolysis at low temperatures, a significant decrease of the final coke product is noticed. Poultry manure pyrolysis results as a suitable and simple solution to be employed for waste treatment purposes, as its combustible effects (combustible gases and semicoke / coke) are good candidates for energy production.
\end{abstract}

Key words. biofuel, poultry manure, pyrolysis, renewable waste, solid biomass

\section{Introduction}

Biofuels employed in energy applications have high oxygen contents and are mainly represented by solid biomass and poultry manure. Solid biomass comes from diverse sources, comprising all species of wood, agricultural (straws, corn stalks, sunflower stalks, seed shells from various crops, etc.) and organic wastes [1]. Even though they have high oxygen content (given by the multiple bounds in organic compounds, it is around $30 \%$ ), these biofuels have also a high moisture content (can get up to 60\%). The high moisture content is a major disadvantage, regardless of the combustion technology, starting from handling operations (including supplying the combustion plants and storage) and ending with the gas thermodynamics in the ignition and combustion process [2].

The rich oxygen content represents an advantage for ignition development, reducing the amount of air necessary for combustion. This positively reflects on the power consumed for the gas flow circuits in combustion plants. Instead, for the pyrolysis process, this oxygen share triggers an internal combustion by heating the fuel under the absence of air [3].

Generally, pyrolysis is a simple process of converting a solid fuel into combustible gas and liquid fuel, with easier application within power plants, reciprocating internal combustion engines and gas turbines [4]. The use of the solid product (coke or semi-coke) for power supply is more difficult due to the lack of volatiles in it, but also to the concentration of heavy metals. Technologically, pyrolysis can be defined as a thermal cracking process, comprising the first stage of the material (the fuel) after the drying process [5]. Thermal cracking leads to fragmentation of organic compounds into lighter molecules. Thus, gaseous components $(\mathrm{CO}, \mathrm{CO} 2, \mathrm{H} 2$, $\mathrm{CH} 4, \mathrm{~N} 2, \mathrm{H} 2 \mathrm{O}$ ), liquid tar and a solid fuel product (semicoke or coke, containing mineral mass) result. The fuel gas has a calorific value between 7 and $13 \mathrm{MJ} / \mathrm{m}^{3} \mathrm{~N}$, and the semi-coke/coke of 15-32 MJ/kg [6]. Depending on the temperature level $(\mathrm{t})$ of the process, the following two types are distinguished:

- $\quad$ semi-pyrolysis, $\mathrm{t}<550^{\circ} \mathrm{C}$;

- pyrolysis, $\mathrm{t} \approx 550-1000^{\circ} \mathrm{C}$. 
The most advanced pyrolysis technologies, currently investigated in detail [7], are:

- Thermolysis process, characterized by a temperature of $420^{\circ} \mathrm{C}$, needs with control over the water vapor elimination and uses an electrically heated reactor;

- Rotorpur process (Germany), characterized by a rotary reactor and a temperature of $700{ }^{\circ} \mathrm{C}$. The rotation of the reactor, by the centrifugal force induced to the material for which pyrolysis is carried out, produces a concentrated film to the hot wall of the reactor; thus, the heat transfer processes are intensified. The heat is produced in a furnace auxiliary to the pyrolysis plant.

In the present paper, implications of oxygen presence in the fuel mass entering in the pyrolysis process is evaluated, with some experimental applications on poultry waste. Most of the time, the poultry waste is mixed with some biomass flooring in the birdhouse (straws or sawdust), which represents about $10-15 \%$ of the total mass, having energy characteristics similar to this waste [8].

\section{Energy characteristics of the high oxygen content biofuels}

Any fuel (including biofuels) can be characterized from an energy point of view based on elemental analysis, using its decomposition into seven elements expressed by gravimetric percentages, as given in eq. (1) [9].

$$
C^{i}+H^{i}+S_{c}^{i}+O^{i}+N^{i}+A^{i}+W_{t}^{i}=100[\%]
$$

The index i defines the initial state. Anhydrous state, with anh notation and fuel mass state, with mc notation are also used often.

The lower calorific power can be determined either by calorimetric means or by calculation based on the elemental composition using eq. (2) [10]:

$$
\begin{gathered}
H_{i}^{i}=339 C^{i}+1029 H^{i}-109\left(O^{i}-S_{c}^{i}\right) \\
-25.1 W_{t}^{i}[\mathrm{~kJ} / \mathrm{kg}]
\end{gathered}
$$

Table 1 presents the energy characteristics for few types of wooden biomass, agricultural biomass and poultry waste [10], [11]. It is notable that all of these biofuels have high oxygen and moisture contents. Different energy characteristics, with a wide range of variation, are registered for household and industrial waste, but they are not the subject of the present research [9], [10].

An important feature of biofuels is represented by their high volatiles content (a fuel mixture of gases released during the heating period of the fuel in the range $250-800{ }^{\circ} \mathrm{C}$ ). The volatiles $\mathrm{Vi}$ are comprised in the technical analysis provided in eq. (3). The maximum of volatiles release is reached in the temperature range of $380-550{ }^{\circ} \mathrm{C}[12]$

$$
C_{f}^{i}+V^{i}+A^{i}+W_{t}^{i}=100[\%]
$$

By comparing the elemental analysis with the technical analysis, it is found that there is a difference between the carbon content $\mathrm{C}_{\mathrm{i}}$ and the one that defines the fixed carbon $\mathrm{C}_{\mathrm{fi}}$, due to the fact that in the technical analysis a part of the carbon is included in the volatiles (e.g. $\mathrm{CO}, \mathrm{CO}_{2}, \mathrm{CH}_{4}$ and other hydrocarbons). Therefore, if an analysis of biofuels combustion with the oxygen in their composition is carried out, a model can be defined using only the oxidation of carbon $\mathrm{C}_{\mathrm{i}}$; this model indirectly includes the combustion of the volatile gases [13]

\section{Particular aspects of pyrolysis technology}

It is highlighted that is preferable to remove, or at least reduce, the moisture content of a biofuel separately from the volatile gases; as a result, pyrolysis with an additional drying step is required. A temperature range of $150-200{ }^{\circ} \mathrm{C}$ is recommended for this drying stage, accelerating the process and keeping the volatiles [14]. The basic concept of the installation employed for the proposed process is shown in Figure 1, where $t_{1}$ and $t_{2}$ represent the temperature at the inlet and at the outlet of the installation.

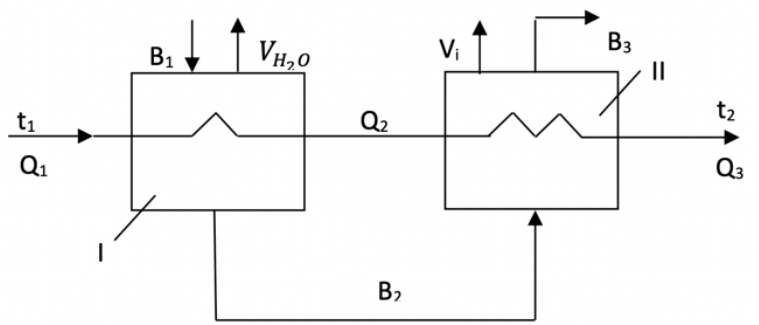

Fig. 1. The two-step pyrolysis process (I. Drying step; II. Pyrolysis step).

Table I. - Energy characteristics of some biofuels [10], [11].

\begin{tabular}{|l|c|c|c|c|c|c|c|c|}
\hline Biofuel & $\begin{array}{c}\boldsymbol{C}^{\boldsymbol{i}} \\
{[\mathbf{\%}]}\end{array}$ & $\begin{array}{c}\boldsymbol{H}^{\boldsymbol{i}} \\
{[\mathbf{\%}]}\end{array}$ & $\begin{array}{c}\boldsymbol{S}_{\boldsymbol{c}}^{\boldsymbol{i}} \\
{[\mathbf{\%}]}\end{array}$ & $\begin{array}{c}\boldsymbol{O}^{\boldsymbol{i}} \\
{[\mathbf{\%}]}\end{array}$ & $\begin{array}{c}\boldsymbol{N}^{\boldsymbol{i}} \\
{[\mathbf{\%}]}\end{array}$ & $\begin{array}{c}\boldsymbol{A}^{\boldsymbol{i}} \\
{[\% \mathbf{\%}]}\end{array}$ & $\begin{array}{c}\boldsymbol{W}_{\boldsymbol{t}}^{\boldsymbol{i}} \\
{[\%]}\end{array}$ & $\begin{array}{c}\boldsymbol{H}_{\boldsymbol{i}}^{\boldsymbol{i}} \\
{[\mathbf{k J} / \mathbf{k g}]}\end{array}$ \\
\hline Sawdust & $27-30$ & $3.5-3.8$ & - & $25.3-26$ & $0.4-0.5$ & $0.1-0.5$ & $40-45$ & $8.3-10.5$ \\
\hline Beech & $12-40$ & $1.4-4.7$ & - & $10-38$ & $0.2-0.5$ & $2.0-6.1$ & $15-75$ & $2.5-14.1$ \\
\hline Elm & $12-40$ & $1.3-4.7$ & - & $10-33$ & $0.2-0.4$ & $0.5-2.1$ & $15-75$ & $2500-14200$ \\
\hline Spruce & $13-44$ & $1.4-4.8$ & - & $10-33$ & $0.1-0.2$ & $0.8-2.6$ & $15-75$ & $3000-16500$ \\
\hline Straws & $41-42.2$ & $4.9-5.2$ & - & $44-45.7$ & $0.1-0.4$ & $4.5-5.8$ & $8-14$ & $13100-16500$ \\
\hline Corn stalks & $38-42$ & $4.2-5.3$ & - & $35-38$ & $1.2-2.6$ & $11-16.8$ & $3.4-5.4$ & $14100-15600$ \\
\hline Ropes of vines & $40-44$ & $3.5-4.5$ & - & $37-45$ & $0.6-2.7$ & $10-27$ & $2.7-4.3$ & $14700-15700$ \\
\hline Poultry manure & $12.1-16.1$ & $4.3-4.9$ & $1.6-1.8$ & $34.3-36.2$ & $1.6-1.8$ & $6.1-6.8$ & $36.1-40.1$ & $3810-5950$ \\
\hline Poultry manure with bed & $12.3-22.5$ & $4.3-5.2$ & $1.7-2.0$ & $35.1-37.4$ & $1.4-2.3$ & $6.1-12.9$ & $34-40$ & $3850-6000$ \\
\hline
\end{tabular}


The heat required for drying is $\mathrm{Q}_{1}-\mathrm{Q}_{2}$, while the heat for pyrolysis itself is $\mathrm{Q}_{2}-\mathrm{Q}_{3}$. From the fuel flow $\left(\mathrm{B}_{1}\right)$ a certain amount of moisture $\left(\mathrm{V}_{\mathrm{H} 2 \mathrm{O}}\right)$ is eliminated within the first step; full drying would be preferable. In the pyrolysis stage, from the anhydrous fuel $\left(\mathrm{B}_{2}\right)$, the volatiles are eliminated, resulting a quantity of coke $\left(\mathrm{B}_{3}\right)$ which also contains the ash percentage $\left(A_{i} / 100\right)$ of the fuel. The following processes can be used:

- semi-pyrolysis, when the final temperature of the process $\mathrm{t}_{2}$ is below $580{ }^{\circ} \mathrm{C}$;

- pyrolysis, when the final temperature of the process is in the range $900-1000{ }^{\circ} \mathrm{C}$.

For the high oxygen content fuels semi-pyrolysis is recommended, as the carbon combustion equation is as in eq. (4):

$$
\mathrm{C}+\mathrm{O}_{2}=2 \mathrm{CO}
$$

Due to the low temperature level, the oxidation cannot go on to $\mathrm{CO}_{2}$ formation, as given by equation (5):

$$
\mathrm{CO}+0.5 \mathrm{O}_{2}=\mathrm{CO}_{2}
$$

Thus, a fuel bed comprising $\mathrm{CO}$ is obtained, further being added to the fuel gas content $\left(\mathrm{H}_{2}, \mathrm{CH}_{4}, \mathrm{CO}\right.$ etc. $)$ obtained by cracking.

For high temperature pyrolysis, due to the fuel oxygen content, the internal oxidation up to $\mathrm{CO}_{2}$ formation reduces the weight of the carbon in the fuel and therefore the weight of the fixed carbon $\left(C_{f}^{j}\right)$ at the end of the pyrolysis. Ultimately, the overall efficiency of the process is reduced. The oxygen volume that will participate in the carbon oxidation reaction is expressed by the ratio $\frac{O_{i}}{100} \rho O_{2}\left[\mathrm{~m}^{3} \mathrm{~N} / \mathrm{kg}\right.$ fuel]; the stoichiometric calculation indicates eq. (6) for carbon consumption $C_{c}$ :

$$
C_{c}=\frac{12 O_{i} / 100}{22.4 \rho O_{2}}=0.377 \frac{o_{i}}{100}[\mathrm{~kg} \text { carbon } / \mathrm{kg} \text { fuel }]
$$

After internal combustion takes place, the carbon content becomes equal to the value given by eq. (7):

$$
C_{\text {real }}^{i}=\frac{C_{i}}{100}-0.377 \frac{o_{i}}{100}[\mathrm{~kg} \text { carbon } / \mathrm{kg} \text { fuel }]
$$

This quantity will lead to the semi-coke or coke amount contained in the final product of the process. It is remarked that, for an oxygen content $O_{i}=30 \%$ (representative for a wide range of solid biomass), the carbon content will be reduced according to eq. (8):

$$
C_{c}=0.377 \cdot 30=11.3[\mathrm{~kg} \text { carbon } / \mathrm{kg} \text { fuel }]
$$

As a result of this oxidation reaction, the amount of carbon that will eventually remain in the fuel is given by eq. (9):

$$
\frac{C_{\text {real }}^{i}}{100}=\frac{C_{i}}{100}-\frac{0.113}{100}[\mathrm{~kg} \text { carbon } / \mathrm{kg} \text { fuel }]
$$

For $C^{i} \approx 40 \%$, a representative value for biomass, the real carbon will be equal to:

$$
C_{\text {real }}^{i}=0.4-0.113=0.287[\mathrm{~kg} \text { carbon } / \mathrm{kg} \text { fuel }]
$$

So, the percentage reduction is evaluated at:

$$
\frac{0.287}{0.4} 100=71.75[\%]
$$

The gas content released by carbon combustion with the oxygen from fuel, which adds to the volatiles, will be as follows:

- in the semi-pyrolysis case:

$$
V_{C O}=3.73 \frac{C_{C}}{100}=1.4 \frac{O_{i}}{100}\left[\mathrm{~m}^{3} \mathrm{~N} / \mathrm{kg} \text { fuel }\right]
$$

- $\quad$ in the pyrolysis case:

$$
V_{\mathrm{CO}_{2}}=1.867 \frac{C_{C}}{100}=0.7 \frac{O_{i}}{100}\left[\mathrm{~m}^{3}{ }_{\mathrm{N}} / \mathrm{kg} \text { fuel }\right]
$$

Conducting semi-pyrolysis experiments at a temperature of $550{ }^{\circ} \mathrm{C}$ on poultry manure led to the following results (using the notations in Figure 1):

- moisture removed: $V_{\mathrm{H}_{2} \mathrm{O}}=0.4 \mathrm{~kg} / \mathrm{kg}$ fuel;

- $\quad$ volatiles, including carbon oxide from the internal oxidation: $V_{i}=0.5 \mathrm{~kg}_{\mathrm{vol}} / \mathrm{kg}$ fuel;

- $\quad$ coke, $B_{3}=10 \% \mathrm{~kg}_{\text {cocs }} / \mathrm{kg}$ fuel.

Compared to the fix carbon that had $C_{f}^{i}=0.33$, the semicoke decreased significantly. Conducting an elemental analysis of the semi-coke in mixture with the ash resulted in obtaining a $9481.3 \mathrm{~kJ} / \mathrm{kg}$ calorific value.

\section{Conclusion}

The paper addresses the carbon oxidation in biofuels during the pyrolysis processes. For the low-temperature pyrolysis, the oxidation leads to the formation of $\mathrm{CO}$ combustible gas, which is added to the volatiles. Instead, for high-temperature pyrolysis, $\mathrm{CO}_{2}$ will form, so that the oxidized carbon will lead to energy loss.

Pilot scale research facility for a low-temperature pyrolysis process of poultry manure has emphasized the above-mentioned issues.

The reduction of the final quantity of coke (semi-coke), evaluated at up to $72 \%$, may lead to an energy loss, highlighted by crucial aspects in the general energy balance.

\section{Acknowledgement}

This work was supported by a grant of the Romanian Ministry of Research and Innovation, CCCDI-UEFISCDI, project number PN-III-P2-2.1-PED- 2019-2350, within PNCDI III (contract number 322PED/2020) and project number PN-III-P1-1.2-PCCDI-20170404/31PCCD/2018, within PNCDI.

\section{References}

[1] P. De Filippis, M. Scarsella, N. Verdone, and M. Zeppieri, "Poultry litter valorization to energy," WIT Trans. Ecol. Environ., vol. 109, pp. 261-267, 2008.

[2] C. R.-N. Joseph R. V. Flora, "Availability of poultry manure as a potential bio-fuel feedstock for energy production," 2006.

[3] L. Mihaescu et al., "Achievements in energy 
valorization of cereal straw in boiler manufactured in Romania," in 5th International Conference on Trends in Agricultural Engineering, 2013, pp. 417-421.

[4] F. Cotana, V. Coccia, A. Petrozzi, G. Cavalaglio, M. Gelosia, and M. C. Merico, "Energy valorization of poultry manure in a thermal power plant: Experimental campaign," Energy Procedia, vol. 45, pp. 315-322, 2014.

[5] L. Mihaescu, G. Lazaroiu, I. Pisa, D.-A. Ciupageanu, and $\mathrm{V}$. Berbece, "Energy valorization of poultry manure through products resulted in a pyrolysis process," in 18th International Multidisciplinary Scientific GeoConference SGEM2018, 2018, pp. 349-355.

[6] M. F. Demirbas, M. Balat, and H. Balat, "Potential contribution of biomass to the sustainable energy development," Energy Convers. Manag., 2009.

[7] R. Rath, P. Kumar, S. Mohanty, and S. K. Nayak, "Recent advances, unsolved deficiencies, and future perspectives of hydrogen fuel cells in transportation and portable sectors," Int. J. Energy Res., no. May, pp. 8931-8955, 2019.

[8] P. Billen, J. Costa, L. Van Der Aa, J. Van Caneghem, and C. Vandecasteele, "Electricity From Poultry Manure: A Cleaner Alternative To Direct Land Application," $J$. Clean. Prod., vol. 96, 2014.

[9] G. Lazaroiu et al., "Biomass combustion with hydrogen injection for energy applications," Energy, vol. 127, pp. 351-357, 2017.

[10] G. Lazaroiu et al., "Experimental Investigations of Innovative Biomass Energy Harnessing Solutions," Energies, vol. 11, no. 12, p. 3469, Dec. 2018.

[11] L. Mihaescu, G. Lazaroiu, I. Pisa, E. Pop, and G. Negreanu, "Research and experimental analyses concerning the increase efficiency of solid biomass combustion in hydrogen jet," in 3 nd International Conference on Thermal Equipment, Renewable Energy and Rural Development, 2014.

[12] B. P. Kelleher, J. J. Leahy, A. M. Henihan, T. F. O'Dwyer, D. Sutton, and M. J. Leahy, "Advances in poultry litter disposal technology - A review," Bioresour. Technol., vol. 83, no. 1, pp. 27-36, 2002.

[13] G. Quiroga, L. Castrillón, Y. Fernández-Nava, and E. Marañón, "Physico-chemical analysis and calorific values of poultry manure," Waste Manag., vol. 30, no. 5, pp. 880-884, 2010.

[14] L. Mihaescu, G. Lazaroiu, I. Pisa, G.-P. Negreanu, V. Berbece, and D.-A. Ciupageanu, "Thermal conditions required for poultry manure combustion in furnace boilers," in 19th International Multidisciplinary Scientific Geoconference SGEM2019, Volume 19(4.1), 2019, pp. 569-576. 